\title{
Population pharmacokinetics of epsilon-aminocaproic acid in infants undergoing craniofacial reconstruction surgery
}

\author{
P. A. Stricker ${ }^{1 *}$, A. F. Zuppa ${ }^{1,3,4}$, J. E. Fiadjoe ${ }^{1}$, L. G. Maxwell ${ }^{1}$, E. M. Sussman ${ }^{1}$, E. Y. Pruitt ${ }^{1}$, T. K. Goebel ${ }^{1}$, \\ M. R. Gastonguay ${ }^{5}$, J. A. Taylor ${ }^{2}$, S. P. Bartlett ${ }^{2}$ and M. S. Schreiner ${ }^{1}$ \\ ${ }^{1}$ Department of Anesthesiology and Critical Care, ${ }^{2}$ Department of Surgery, ${ }^{3}$ Division of Critical Care Medicine, Department of \\ Anesthesiology and Critical Care Medicine and ${ }^{4}$ Division of Clinical Pharmacology and Therapeutics, Department of Pediatrics, \\ The Children's Hospital of Philadelphia, Perelman School of Medicine at the University of Pennsylvania, Philadelphia, PA, USA \\ ${ }^{5}$ Metrum Institute, Tariffville, CT, USA \\ * Corresponding author: Department of Anesthesiology and Critical Care Medicine, The Children's Hospital of Philadelphia, 34th Street and \\ Civic Center Boulevard, Philadelphia, PA 19104-4399, USA. E-mail: strickerp@email.chop.edu
}

\section{Editor's key points}

- This study aimed at determining the pharmacokinetics (PKs) of antifibrinolytic epsilon-aminocaproic acid (EACA) in infants aged 6-24 months undergoing craniofacial reconstruction surgery.

- The final structural model was a two-compartment disposition model with inter-individual random effects estimated on clearance and central distribution volume.

- EACA PKs is influenced by weight, age, and perioperative conditions.

- The dependence of clearance on body weight supports weight-based dosing.
Background. Understanding the clinical pharmacology of the antifibrinolytic epsilonaminocaproic acid (EACA) is necessary for rational drug administration in children. The aim of this study is to determine the pharmacokinetics (PKs) of EACA in infants aged 6-24 months undergoing craniofacial reconstruction surgery.

Methods. Cohorts of six infants were enrolled sequentially to one of the three escalating loading dose-continuous i.v. infusion (CIVI) regimens: $25 \mathrm{mg} \mathrm{kg}^{-1}, 10 \mathrm{mg} \mathrm{kg}^{-1} \mathrm{~h}^{-1} ; 50$ $\mathrm{mg} \mathrm{kg}^{-1}, 20 \mathrm{mg} \mathrm{kg}^{-1} \mathrm{~h}^{-1} ; 100 \mathrm{mg} \mathrm{kg}^{-1}, 40 \mathrm{mg} \mathrm{kg}^{-1} \mathrm{~h}^{-1}$. Plasma EACA concentrations were determined using a validated high-performance liquid chromatography-tandem mass spectrometry assay. A population non-linear mixed effects modelling approach was used to characterize EACA PKs.

Results. Population PK parameters of EACA were estimated using a two-compartment disposition model with weight expressed as an allometric covariate and an age effect. The typical patient in this study had an age of 38.71 weeks and a weight of $8.82 \mathrm{~kg}$. PK parameters for this typical patient were: pre-/postoperative plasma drug clearance of 32 $\mathrm{ml} \mathrm{\operatorname {min } ^ { - 1 }}$ (3.6 ml kg $\left.\mathrm{min}^{-1}\right)$, inter-compartmental clearance of $42.4 \mathrm{ml} \mathrm{min}{ }^{-1}(4.8 \mathrm{ml}$ $\left.\min ^{-1} \mathrm{~kg}^{-1}\right)$, central volume of distribution of 1.27 litre $\left(0.14\right.$ litre $\left.\mathrm{kg}^{-1}\right)$, and peripheral volume of distribution of 2.53 litre $\left(0.29\right.$ litre $\left.\mathrm{kg}^{-1}\right)$. Intra-operative clearance and central volume of distribution were $89 \%$ and $80 \%$ of the pre-/postoperative value, respectively.

Conclusions. EACA clearance increased with weight and age. The dependence of clearance on body weight supports weight-based dosing. Based on this study, a loading dose of 100 $\mathrm{mg} \mathrm{kg}^{-1}$ followed by a CIVI of $40 \mathrm{mg} \mathrm{kg}^{-1} \mathrm{~h}^{-1}$ is appropriate to maintain target plasma EACA concentrations in children aged 6-24 months undergoing these procedures.

Keywords: aminocaproic acid; antifibrinolytic agents; craniofacial abnormalities; infants; paediatrics; pharmacology

Accepted for publication: 16 November 2012
Intraoperative haemorrhage during paediatric craniofacial reconstruction procedures often exceeds the circulating blood volume, ${ }^{1-3}$ mandating substantial perioperative transfusion. ${ }^{245}$ Transfusion of homologous blood products entails risks of infectious disease transmission, transfusion reaction, and immunosuppression. ${ }^{6-8}$ Efforts to minimize surgical bleeding may translate to reduced transfusion requirements and lessening of associated risks.
The intraoperative administration of antifibrinolytic agents is an increasingly used approach for minimizing blood loss and transfusion. The antifibrinolytic epsilon-aminocaproic acid (EACA) is a synthetic lysine analogue that blocks the lysine-binding sites on plasminogen, resulting in antifibrinolytic activity through inhibition of fibrinolysin formation. ${ }^{9} 10$ EACA has been shown to reduce transfusion requirements in children undergoing procedures on cardiopulmonary 
bypass, as well as in adolescents undergoing spinal surgery for scoliosis. ${ }^{11-16}$ EACA may also be effective in reducing blood loss and transfusion in children undergoing craniofacial surgery; however, efficacy data to support the use for this indication are not yet available.

Before conducting efficacy studies, a firm understanding of the pharmacokinetics (PKs) of EACA in children is needed. Although EACA pharmacology has been well studied in adults, ${ }^{17-21}$ limited paediatric PK data are available to guide therapy or to guide dose selection for clinical trials. ${ }^{22}$ Given the need for PK data before conducting the clinical trials, the primary objective of this study was to describe the PKs of EACA administered to infants aged 2-24 months undergoing craniofacial surgery.

\section{Methods}

\section{Clinical trial}

This open-label, non-randomized, dose escalation, PK trial was conducted under an investigational new drug application (IND 105,301) with the United States Food and Drug Administration and registered at www.clinicalgtrials.gov. After institutional review board approval and written informed parental consent, healthy infants aged 2-24 months undergoing craniofacial surgery without history of renal impairment or a history of a coagulation disorder were eligible for enrolment. Subjects were sequentially enrolled in one of the three cohorts. Each subject received an i.v. loading dose followed by a continuous i.v. infusion (CIVI) of EACA as described below:

\begin{tabular}{lll}
\hline & Loading dose $\left(\mathrm{mg} \mathrm{kg}^{-1}\right)$ & CIVI rate $\left(\mathrm{mg} \mathrm{kg}^{-1} \mathrm{~h}^{-1}\right)$ \\
Cohort 1 & 25 & 10 \\
Cohort 2 & 50 & 20 \\
Cohort 3 & 100 & 40 \\
\hline
\end{tabular}

This dosage range was selected based on the dosing regimen reported in adolescents undergoing spinal fusion of $100 \mathrm{mg}$ $\mathrm{kg}^{-1}$ loading dose followed by a CIVI of $10 \mathrm{mg} \mathrm{kg}^{-1} \mathrm{~h}^{-1} .{ }^{15}$ EACA administration began in the operating theatre after induction of anaesthesia and arterial line insertion. The loading dose was administered over 10 min and was immediately followed by a CIVI that continued until the end of surgery as marked by completion of skin closure. Study enrolment continued until there were six evaluable subjects in each of the three cohorts. Interim PK and safety analyses were performed at the completion of each dosing cohort before escalation to the next higher dose cohort.

Patient characteristics and data pertaining to the medical management and perioperative course of enrolled subjects were collected. Collected data included age, weight, gender, diagnosis, surgical procedure, presence of a craniosynostosis syndrome, duration of surgery, and all fluids and blood products administered intraoperatively. Preoperative, intraoperative, and postoperative laboratory values performed as part of standard care were also recorded. The intensive care unit (ICU) flow sheets, progress notes, and radiologic study results were reviewed to detect the occurrence of adverse events. Intraoperative blood loss was calculated in the manner previously described in this population by Kearney and colleagues ${ }^{23}$ and used in other reports in this population. ${ }^{5} 24$

\section{Conduct of anesthesia}

All subjects received general tracheal anaesthesia with standard American Society of Anesthesiologists monitoring. Mask induction of anaesthesia was performed with sevoflurane, nitrous oxide, and oxygen. Each subject had two peripheral i.v. catheters: a central venous catheter and a radial arterial catheter placed as part of our standard clinical care. Normothermia was facilitated by a circulating warm water blanket, a forced air warmer, and an i.v. fluid warmer. Anaesthesia was maintained with isoflurane, sevoflurane, or desflurane in air and oxygen. Fentanyl or morphine was administered for anaesthetic supplementation and postoperative analgesia. Anaesthetic management, fluid management, and blood loss replacement were at the discretion of anaesthesia providers without a fixed protocol. Standard clinical practice at our institution is to direct fluid and anaesthetic management to maintain a mean arterial pressure $>45 \mathrm{~mm} \mathrm{Hg}$ in these children.

\section{PK sampling}

PK samples, consisting of $1 \mathrm{ml}$ of blood, were drawn immediately before and after the loading dose, after initiation of CIVI $(0.5,2,4-6 \mathrm{~h})$, at the end of the CIVI, and after the end of the CIVI $(0.5,3,6,9,12$, and $15 \mathrm{~h})$, for a maximum total of 12 PK samples. All intraoperative PK samples were drawn from the arterial catheter. Postoperative PK samples were drawn from an arterial catheter or central venous catheter; nearly all were arterial. Plasma was separated by centrifugation and stored at $-80^{\circ} \mathrm{C}$.

\section{Drug quantitation}

EACA plasma concentrations were determined using a validated high-performance liquid chromatography-tandem mass spectrometry assay with a lower limit of quantitation of $1 \mu \mathrm{g} \mathrm{ml}^{-1}$. The intraday precision based on the standard deviation of replicates of quality control samples ranged from $0.3 \%$ to $2 \%$ with accuracy ranging from $89 \%$ to $102 \%$. The method was validated for EACA concentrations of $1-250 \mathrm{mg}$ litre $^{-1}$.

\section{Pharmacostatistical analysis}

\section{Model building}

The population PK analysis was conducted using non-linear-mixed effects methods (NONMEM ${ }^{\circledR}$ software, ICON Development Solutions, Ellicott City, MD, USA, version VI, level 2.0 with subroutines ADVAN 3, TRANS 4). All models were run with the first-order conditional estimation with interaction (FOCE-I) method. S-Plus Version 6.2 (Insightful, Inc., Data Analysis Products Division, Seattle, WA, USA) was used for goodness-of-fit diagnostics and graphical 
displays. The goodness-of-fit from each model run was assessed by the examination of the following criteria: diagnostic plots, the standard errors of the parameters, global minimization of the search algorithm, the Akaike Information Criterion which is equal to the minimum objective function value (MOFV) plus two times the number of parameters, and plausibility of parameter estimates.

\section{Base model}

One, two, and three-compartment models were investigated. A two-compartment disposition model was selected to define the EACA plasma concentration profile based on results from the model building process and previously published data. ${ }^{9} 17$ Models were parameterized by clearance $(\mathrm{CL}$, $\left.\mathrm{ml} \min ^{-1}\right)$, inter-compartmental clearance $\left(\mathrm{Q}, \mathrm{ml} \mathrm{min}^{-1}\right)$, central volume of distribution (V1, litres), and peripheral volume of distribution (V2, litres). The one-compartment model was inadequate to describe the data. The added complexity of the three-compartment model was not supported by the data.

An exponential variance model was used to describe the variability of $\mathrm{PK}$ parameters across individuals in the form: $P_{i}=\theta_{k} \exp \left(\eta_{k i}\right)$, where $P_{i}$ is the estimated parameter value for the individual subject $i, \theta_{k}$ is the typical population value of parameter $k, \eta_{k i}$ are the inter-individual random effects for individual $i$ and parameter $k$. Inter-individual variability was initially estimated for clearance, and then subsequently for the remaining PK parameters.

Additive, proportional, and combined (additive and proportional) residual error models were considered during the model-building process. Ultimately, a combined additive and proportional error model was used to describe random residual variability: $C_{\mathrm{obs}, i j}=\left[C_{\mathrm{pred}, i j} \times\left(1+\varepsilon_{i j p}\right)\right]+\varepsilon_{i j \mathrm{~A}}$, where $C_{\text {obs }, i j}$ is the observed concentration $j$ in individual $i, C_{\text {pred }, i j}$ is the individual predicted concentration, $\varepsilon_{i j \mathrm{p}}$ is the proportional residual random error, and $\varepsilon_{i j \mathrm{~A}}$ is the additive residual random error for individual $i$ and measurement $j$.

The impact of weight on all parameters was implemented using an allometric model: TVP $=\theta_{\mathrm{TVP}} \times\left(\mathrm{WT}_{\mathrm{i}} / \mathrm{WT}_{\text {ref }}\right)^{\theta \text { allometric }}$, where TVP is the typical value of a model parameter, described as a function of body weight, $\theta_{\text {TVP }}$ is an estimated parameter describing the typical PK parameter value for an individual with weight equal to the reference weight, $\mathrm{WT}_{\mathrm{i}}$ is an individual subject's body weight and $W_{\text {ref }}$ is the reference value $\left(8.82 \mathrm{~kg}\right.$ for this analysis), and $\theta^{\text {allometric }}$ is an allometric power parameter based on physiologic consideration of size impact on metabolic processes and is fixed at a value of 0.75 for clearances, and a value of 1 for volumes. $^{25}$

\section{Full covariate model}

A full covariate model was constructed to make inferences about effects of covariates on EACA disposition. Covariate effects were pre-defined based on clinical interest, prior knowledge, and physiologic plausibility. The analysis was focused on estimation of effects and avoided the problem of selection bias, which is particularly problematic with stepwise model building in small data sets. ${ }^{26} 27$ The effects of age, intra- vs postoperative status, and blood loss were evaluated in this model.

\section{Simulations}

The full covariate model was used to simulate expected concentration-time profiles under various dosing scenarios. Five hundred Monte Carlo simulation replicates were performed to determine the optimal dose to achieve plasma steady-state concentrations $>130 \mathrm{mg}$ litre $^{-1}$, which have been associated with therapeutic EACA effects. ${ }^{28}{ }^{29}$ A bolus dose over 10 min followed by a 240 min infusion was simulated for the median subject $(8.82 \mathrm{~kg}$ child, 38 weeks of age), the youngest subject in the cohort ( $7.7 \mathrm{~kg}, 27$ weeks) and the oldest child in the cohort $(11.8 \mathrm{~kg}, 107$ weeks), who all had an operative procedure of $240 \mathrm{~min}$. The median concentration and the $95 \%$ confidence interval were estimated.

\section{Safety monitoring}

All subjects who received at least the loading dose of EACA were part of the safety population. All enrolled subjects had the following preoperative laboratory tests: complete blood count, prothrombin time (PT), activated partial thromboplastin time (aPTT), blood urea nitrogen (BUN), and serum creatinine. Subjects who consented but who had preoperative laboratory evidence of abnormal renal function, coagulation derangement, or haematologic abnormality on screening laboratory testing were considered screen failures and were not eligible to receive study drug.

A dose-limiting toxicity (DLT) was defined as a decrease in mean arterial blood pressure of $>30 \%$ of the baseline value during EACA loading dose administration or any serious adverse event possibly, probably, or definitely related to EACA administration. In the event that two of the six subjects in a dosing cohort experienced a DLT, three additional subjects to a maximum of nine would have been enrolled in that dosing cohort. The maximum tolerated dose for EACA would have been exceeded if one additional subject demonstrated a DLT, and no additional subjects would be studied in that dosing cohort. All subjects had the following testing on postoperative day 1 for safety evaluation: BUN, creatinine, PT, aPTT, serum aspartate aminotransferase, serum alanine transaminase (ALT), and total bilirubin level. After completion of enrolment of each cohort and before dose escalation to the next cohort, EACA assays were performed and adverse events were reviewed with the study medical monitor (a physician not involved in the conduct of the study).

\section{Results}

\section{Study conduct}

One hundred and eighty-two potentially eligible subjects were screened for enrolment. Of these, 43 subjects met the initial eligibility criteria and 39 subjects were approached for enrolment. Of these, 18 subjects were enrolled in the 
Table 1 Subject patient characteristics

\begin{tabular}{lccclll}
\hline & ID & Weight (kg) & Age (weeks) & Gender & Diagnosis & Procedure \\
\hline Cohort 1 & 1 & 7.7 & 27.4 & Female & Unicoronal synostosis & Fronto-orbital advancement \\
& 2 & 9.6 & 38.9 & Male & Metopic synostosis & Fronto-orbital advancement \\
& 3 & 7.9 & 31.6 & Male & Lambdoid synostosis & Posterior cranial vault reconstruction \\
& 4 & 11.4 & 85.9 & Female & Pfeiffer syndrome & Fronto-orbital advancement \\
& 5 & 8.3 & 38.6 & Female & Unicoronal synostosis & Fronto-orbital advancement \\
& 6 & 7.8 & 34.6 & Female & Saethre-Chotzen syndrome & Fronto-orbital advancement \\
Cohort 2 & 7 & 10.8 & 67.1 & Male & Sagittal synostosis & Fronto-orbital advancement \\
& 8 & 6.7 & 69.4 & Female & Metopic synostosis & Fronto-orbital advancement \\
& 9 & 8.9 & 99 & Female & Metopic synostosis & Fronto-orbital advancement \\
& 10 & 6.8 & 33 & Male & Unicoronal synostosis & Fronto-orbital advancement \\
& 11 & 9.9 & 34.9 & Male & Metopic synostosis & Fronto-orbital advancement \\
& 12 & 7.4 & 30.6 & Female & Metopic synostosis & Fronto-orbital advancement \\
& 13 & 8.7 & 35 & Female & Metopic synostosis & Fronto-orbital advancement \\
& 14 & 11.8 & 106.9 & Female & Sagittal synostosis & Posterior cranial vault reconstruction \\
& 15 & 9.1 & 42.1 & Female & Metopic synostosis & Fronto-orbital advancement \\
& 16 & 10.9 & 48.7 & Male & Metopic synostosis & Fronto-orbital advancement \\
& 17 & 7.1 & 36.4 & Male & Metopic synostosis & Fronto-orbital advancement \\
& 18 & 10.2 & 43.7 & Male & Unicoronal synostosis & Fronto-orbital advancement \\
\hline
\end{tabular}

Table 2 Intraoperative calculated blood loss and i.v. fluid and transfusion volumes

\begin{tabular}{lrlrlr}
\hline Subject \# & Weight (kg) & $\begin{array}{l}\text { Calculated blood } \\
\text { loss (blood volumes) }\end{array}$ & Calculated blood loss $(\mathbf{m l})$ & Lactated Ringer's (ml) & Reconstituted blood (ml) \\
\hline 1 & 7.7 & 0.2 & 118 & 300 & 110 \\
2 & 9.6 & 1.0 & 920 & 200 & 750 \\
3 & 7.9 & 0.5 & 345 & 200 & 225 \\
4 & 11.4 & 1.1 & 1170 & 350 & 975 \\
5 & 8.3 & 1.2 & 1001 & 550 & 840 \\
6 & 7.8 & 0.9 & 571 & 500 & 500 \\
7 & 10.8 & 1.7 & 1676 & 825 & 1300 \\
8 & 6.7 & 0.4 & 242 & 300 & 170 \\
9 & 8.9 & 1.0 & 822 & 700 & 600 \\
10 & 6.8 & 1.0 & 580 & 455 & 405 \\
11 & 9.9 & 1.4 & 1334 & 350 & 935 \\
12 & 7.4 & 2.0 & 1284 & 425 & 1030 \\
13 & 8.7 & 1.1 & 930 & 350 & 600 \\
14 & 11.8 & 1.2 & 1317 & 350 & 1083 \\
15 & 9.1 & 1.0 & 907 & 600 & 760 \\
16 & 10.9 & 0.4 & 412 & 300 & 220 \\
17 & 7.1 & 1.7 & 1079 & 250 & 910 \\
18 & 10.2 & 0.9 & 821 & 450 & 630
\end{tabular}

study, all of whom were subsequently included in the PK analysis. Patient characteristics of evaluable subjects are presented in Table 1. The median age and weight of the subjects were 39 weeks and $8.8 \mathrm{~kg}$, respectively. Intraoperative fluid administration and calculated blood loss are presented in Table 2. The median (range) duration of the CIVI was 230 (111-342), 227 (169-365), and 254 (219-280) $\mathrm{min}$ in cohorts 1,2 , and 3 , respectively, with an overall median duration of infusion of $243 \mathrm{~min}$.

\section{PK modelling and simulation}

Concentration-time profiles are presented in Figure 1. The final structural model was a two-compartment disposition model with inter-individual random effects estimated on $\mathrm{CL}$ and V1. The addition of inter-individual variability estimates on $Q$ and $V 2$ resulted in over-parameterization of the model, as evidenced by failure of the covariance step, and these terms were not included in the final model. Using FOCE-I estimation, the base model minimized with 

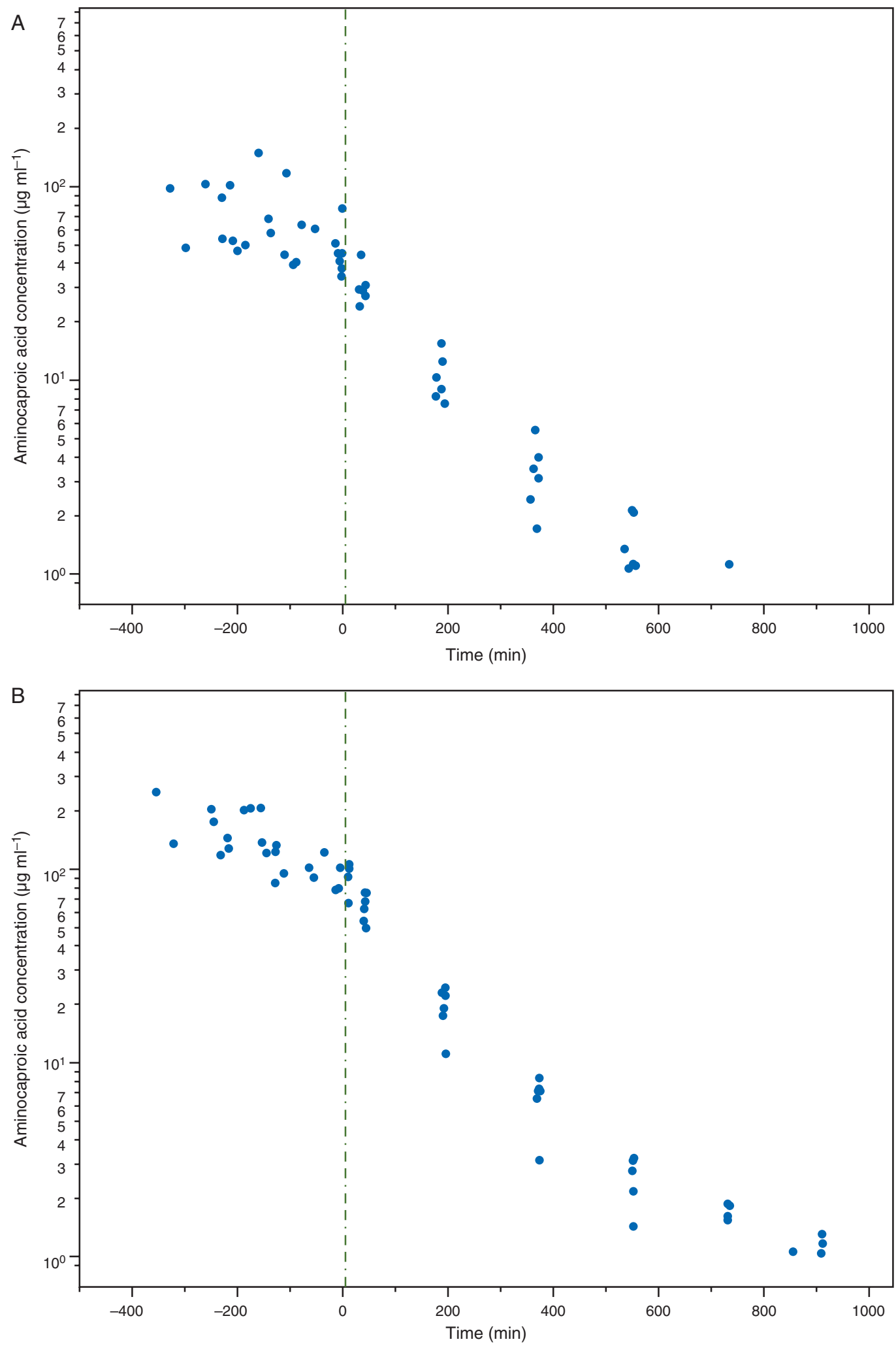

Fig 1 Semi-logarithmic concentration-time plots for aminocaproic acid for the three dosing cohorts. Pre-bolus concentrations are omitted (all less than the lower limit of quantitation). Plasma concentrations obtained before and after end of infusion (time 0 ) are shown. End of infusion occurs at $0 \mathrm{~h}$. (A) Dosing cohort 1: intravenous loading dose administered over $10 \mathrm{~min}$ of $25 \mathrm{mg} \mathrm{kg}^{-1}$ followed by a CIVI of $10 \mathrm{mg} \mathrm{kg}^{-1} \mathrm{~h}^{-1}$. (B) Dosing cohort 2: loading dose of $50 \mathrm{mg} \mathrm{kg}^{-1}$ followed by a CIVI of $20 \mathrm{mg} \mathrm{kg}^{-1} \mathrm{~h}^{-1}$. (c) Dosing cohort 3: loading dose of $100 \mathrm{mg} \mathrm{kg}^{-1}$ followed by a CIVI of $40 \mathrm{mg} \mathrm{kg}^{-1} \mathrm{~h}^{-1}$. 


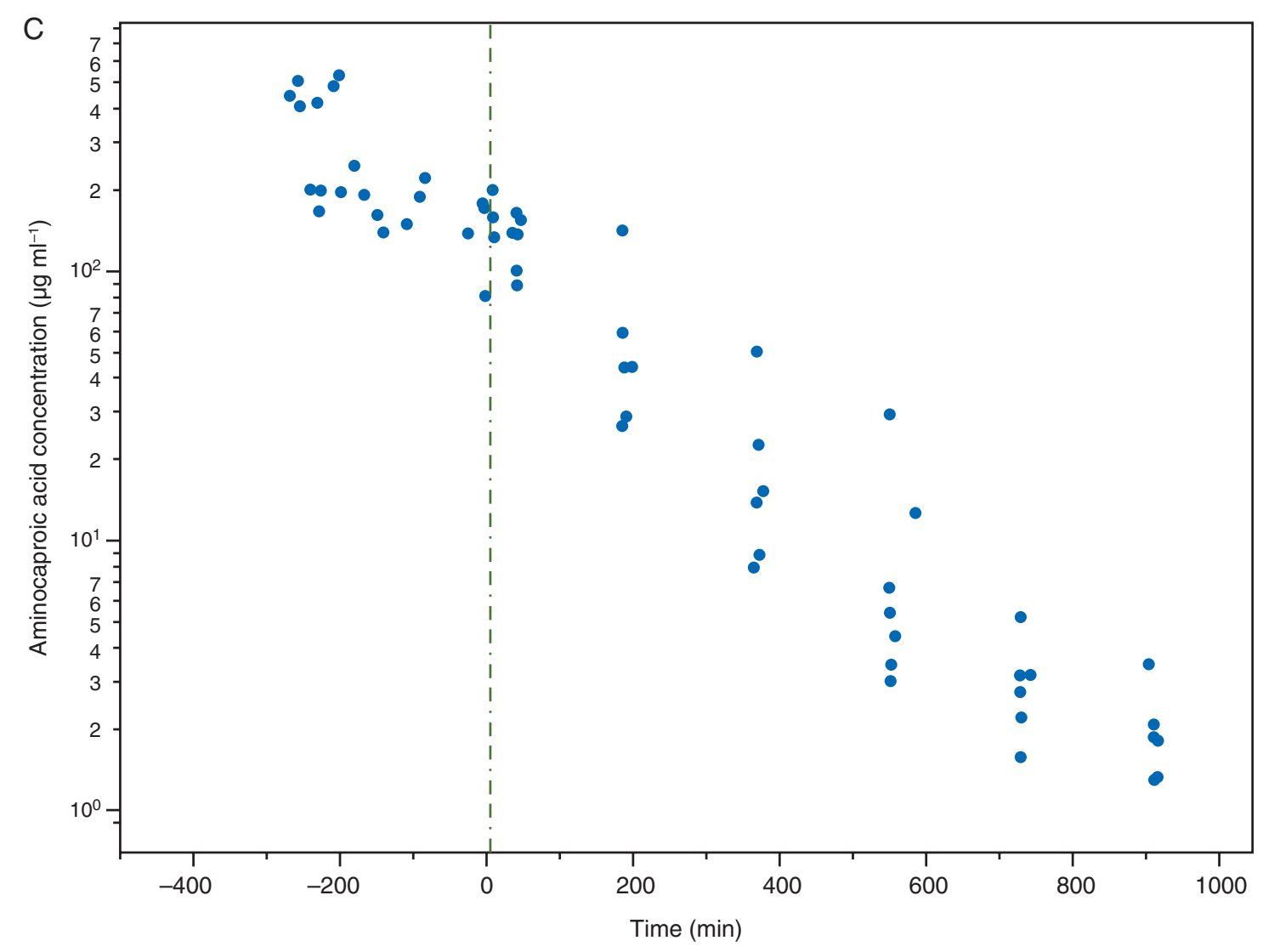

Fig 1 Continued

successful execution of the covariance matrix of the estimates. Scaling the PK parameters allometrically to weight resulted in a 29-point improvement in the minimal value of the objective function when compared with a model without weight. The full covariate model was developed by simultaneously including effects for covariates of clinical interest and those with physiological plausibility. Table 3 demonstrates key modelling steps in the development of the full PK model.

The impact of intra-operative blood loss on PKs was of clinical interest. Given the study design, however, this covariate was temporally correlated with the intra-operative period, and any associated physiological or pharmacological changes during that time. Consequently, a definitive estimation of intra-operative blood loss effects was not possible. The difference between intra- and pre-/postoperative $\mathrm{CL}$ and V1 was estimated in the modelling effort, and this effect is understood to include the impact of blood loss and other changes during the intra-operative period. The intra-operative period (the time when bleeding occurred) was defined as the time immediately after the post-loading dose PK sample through the end of the surgery. The differences in $C L$ and $V 1$ were estimated for this period relative to the pre-/postoperative period. There was an $11 \%$ (SE
7.9\%) reduction in $\mathrm{CL}$ during the intra-operative period, and a $20 \%$ reduction in V1 (SE $16.6 \%$ ).

Review of the exploratory graphics of the random effects for $\mathrm{CL}$ demonstrated that a strong correlation between age and $C L$ (Fig. 2A) remained after the addition of weight as a covariate. The addition of age as a covariate on $\mathrm{CL}$ resulted in an improvement in the random effects for $\mathrm{CL}$ vs age (Fig. 2B). The model for the age-related maturational effect on $\mathrm{CL}$ was implemented as an asymptotically increasing maximum effect model. The model-estimated age at which $50 \%$ of full CL was achieved was 7.36 (55.4\% SE) weeks. The precision of this parameter reflects the fact that the observed age range lower bound was 24 weeks. Given this point estimate, however, it is expected that $90 \%$ of full maturation $\mathrm{CL}$ should occur at $\sim 66$ weeks.

Observed vs population and individual predicted values revealed no systematic bias in the prediction of plasma concentrations for the entire study (Fig. 3). Final parameter estimates, inter-individual variability, and residual variability are represented in Table 4, with the respective standard errors of the point estimates. Table 5 reports $\mathrm{CL}$ and $\mathrm{V} 1$ for various weight groups without an age effect. We estimate the typical values of pre-/postoperative $\mathrm{CL}$ for a $70 \mathrm{~kg}$ adult to be $177.7 \mathrm{ml} \mathrm{min}^{-1} 70 \mathrm{~kg}$. 
Table 3 Key modelling steps in the development of the full PK model. BSV, between-subject variability; MOFV, minimum objective function value

\begin{tabular}{|c|c|c|c|c|c|c|}
\hline Run & Original run & Comments & MOFV & $\begin{array}{l}\text { Change in } \\
\text { MOFV }\end{array}$ & $\begin{array}{l}\text { Execution of } \\
\text { covariance step }\end{array}$ & Comments \\
\hline 1 & & No weight, BSV on CL and V1 & 872 & & Yes & \\
\hline 2 & 1 & Weight added & 843 & -29 & Yes & \\
\hline 3 & 2 & Add BSV to Q & 831 & -12 & No & $\begin{array}{l}\text { Improvement in MOFV but failure } \\
\text { of covariance step }\end{array}$ \\
\hline 4 & 2 & Add BSV to V2 & 837 & -6 & No & $\begin{array}{l}\text { Improvement in MOFV but failure } \\
\text { of covariance step }\end{array}$ \\
\hline 6 & 2 & Age added & 841 & -2 & Yes & Improvement in random effects \\
\hline 10 & 5 & $\begin{array}{l}\text { Difference in } \mathrm{CL} \text { and } \mathrm{V} 1 \text { pre/ } \\
\text { postoperative vs intraoperative }\end{array}$ & 836 & -5 & Yes & Final model \\
\hline
\end{tabular}
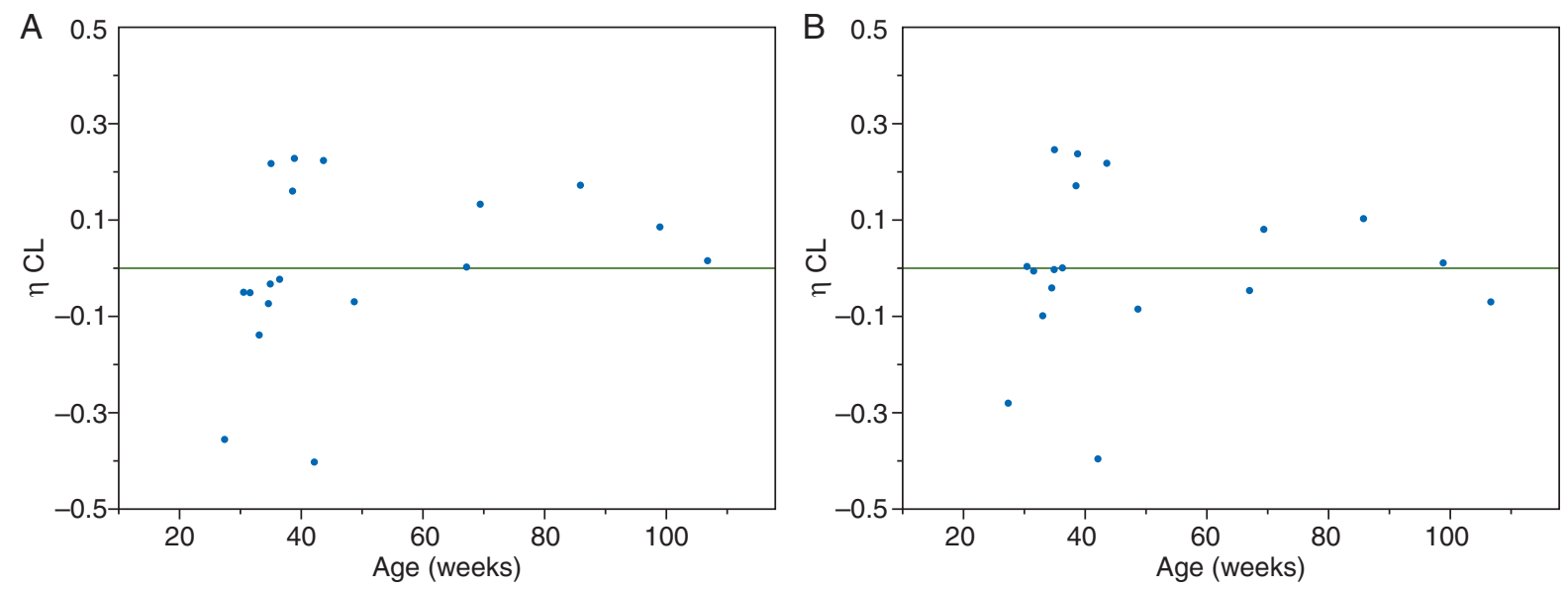

Fig 2 Random effects $(\eta)$ for $C L$ vs age from the weight model (A) and final (B) models.

Dosing scenarios were explored by simulation with the final model. These simulations predicted that a loading dose of $100 \mathrm{mg} \mathrm{kg}^{-1}$ followed by a continuous infusion of $40 \mathrm{mg} \mathrm{kg}^{-1} \mathrm{~h}^{-1}$ for $4 \mathrm{~h}$ would be expected to maintain a steady-state plasma concentration of $\sim 130 \mathrm{mg}^{\text {litre }}{ }^{-1}$ in $\sim 95 \%$ of subjects for the duration of the infusion for the median subject ( $8.82 \mathrm{~kg}$ child, 38 weeks of age). Similar concentrations were achieved for the youngest subject in the cohort $(7.7 \mathrm{~kg}, 27$ weeks) and the oldest child in the cohort (11.8 kg, 107 weeks) with the same dosing strategy (Fig. 4).

\section{Safety evaluation}

No subject in this study experienced a DLT. No adverse events were identified to be possibly, probably, or definitely related to EACA administration.

\section{Discussion}

A typical infant in this study (median weight of $8.82 \mathrm{~kg}, 38.7$ weeks) undergoing craniofacial reconstruction surgery had a pre-/postoperative plasma drug clearance of $32 \mathrm{ml} \mathrm{min}^{-1}$ (3.6 $\mathrm{ml} \mathrm{kg}^{-1} \mathrm{~min}^{-1}$ ), inter-compartmental clearance of 42.4 $\mathrm{ml} \mathrm{min}{ }^{-1}\left(4.8 \mathrm{ml} \mathrm{min}{ }^{-1} \mathrm{~kg}^{-1}\right)$, central volume of distribution of 1.27 litre ( 0.14 litre $\left.\mathrm{kg}^{-1}\right)$, and peripheral volume of distribution of 2.53 litre $\left(0.29\right.$ litre $\left.\mathrm{kg}^{-1}\right)$ based on a twocompartment population PK model. Intra-operative clearance and central volume of distribution were $89 \%$ and $80 \%$ of the pre-/postoperative value, respectively. Age effect on $\mathrm{CL}$ remained after accounting for weight, and was poorly estimated as demonstrated by the per cent standard error. Maturation of $C L$ was described with a half-maximal capacity by $\sim 7.3$ weeks, and full maturation by 66 weeks. Because all intraoperative blood loss occurred more than 10 min after the completion of the loading dose, values for V1 derived from the intra-operative period should not be used when determining the loading dose. The intra-operative V1 was less than that of the pre- and postoperative settings. The use of the intra-operative value therefore would result in an underestimation of the required loading dose.

Previous studies have shown that renal excretion serves as the primary route of EACA elimination, whether administered 

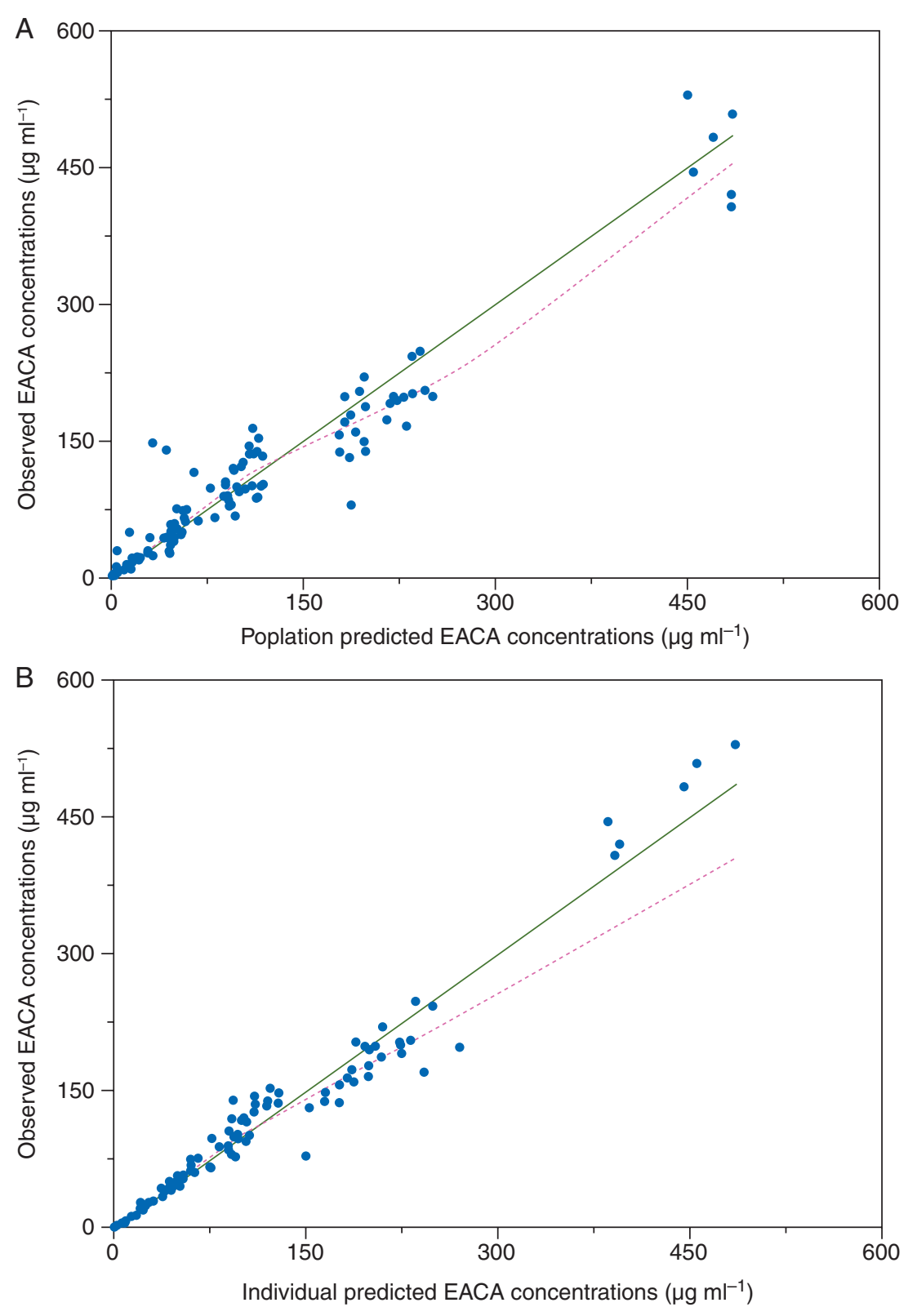

Fig 3 Observed vs population (A) and individual (B) predicted concentrations for the full model. A loess smoother is represented by the dashed line.

orally or i.v. ${ }^{9}{ }^{30-32}$ Approximately $65-75 \%$ of the dose is recovered in the urine as unchanged drug while $\sim 11 \%$ of the dose appears as the metabolite adipic acid. ${ }^{9} 17$ 30-32 Based on our data, we estimate a typical postoperative clearance of $184.4 \mathrm{ml} \mathrm{min}^{-1}$ for a $70 \mathrm{~kg}$ person, which compares favourably to the previously reported clearance of $190 \mathrm{ml}$ $\mathrm{min}^{-1}$ for a $70 \mathrm{~kg}$ adult $\left(157 \mathrm{ml} \mathrm{h}^{-1} \mathrm{~kg}^{-1}\right)$ reported by Frederiksen and colleagues ${ }^{9}$ and the clearance of $124 \mathrm{ml} \mathrm{min}^{-1}$ (106 $\mathrm{ml} \mathrm{h}^{-1} \mathrm{~kg}^{-1}$ ) reported by Dvorchik and colleagues. ${ }^{33}$ We hypothesize that EACA has a high extraction ratio and that intra-operative clearance is less than postoperative clearance possibly because of anaesthetic-related decreases in blood pressure, cardiac output or both, resulting in less renal perfusion and, therefore, a decrease in the perfusionlimited CL.

The therapeutic plasma concentration of EACA to control systemic fibrinolytic activity was determined to be $130 \mathrm{mg}$ litre $^{-1}\left(1 \mathrm{mmol}\right.$ litre $\left.^{-1}\right)$ in 1959. ${ }^{28} 29$ Dosing strategies based on PK studies in adults ${ }^{18} 19$ and children ${ }^{22}$ have been targeted to maintain plasma EACA levels at or above this concentration. Based on our data, an EACA loading dose of $100 \mathrm{mg} \mathrm{kg}^{-1}$ administered over $10 \mathrm{~min}$ followed by a CIVI of $40 \mathrm{mg} \mathrm{kg}^{-1} \mathrm{~h}^{-1}$ would yield therapeutic plasma EACA concentrations for the typical subject (38 weeks, $8.82 \mathrm{~kg}$ ). The PK 
model described provides our best understanding of drug disposition. The model was used to evaluate a simpler dosing rule that is commonly used as a standard of care. This dosing strategy was not model derived. A simpler dosing rule for clinical use was proposed, and this was evaluated using the rigorous model. The dosing rule that is used in clinical practice achieved target concentrations when evaluated by the PK model, and therefore more complex dosing rules are not indicated for use at the bedside. Frederiksen and colleagues reported that the peak antifibrinolytic effects of EACA occurred 15-60 min after peak plasma concentrations were achieved. ${ }^{9}$ Accordingly, the completion of the loading dose should occur at least 15 min before surgery begins.

Table 4 Parameter estimates from the full covariate EACA population pharmacokinetic model. SE\%=(standard error/ parameter estimate) $\times 100$. Between-subject variability $=$ (square-root of variance) $\times 100$. Covariance between $\mathrm{CL}$ and V1 random effects was 0.03 (102\% SE). Postoperative $\mathrm{CL}=\theta_{\mathrm{CL}} \times(\mathrm{WT} / 8.82)^{0.75} \times($ age $) /(7.36+$ age $)$. Intra-operative $\mathrm{CL}$ $=$ post-/postoperative $\mathrm{CL} \times 0.89 . \mathrm{V} 1=\theta_{\mathrm{V} 1} \times(\mathrm{WT} / 8.82)^{1}$. Intra-operative $\mathrm{V} 1$ =post-/postoperative $\mathrm{V} 1 \times 0.8 . Q=\theta_{\mathrm{Q}} \times(\mathrm{WT} /$ $8.82)^{0.75} \cdot \mathrm{V} 2=\theta_{\mathrm{V} 2} \times(\mathrm{WT} / 8.82)^{1}$

\begin{tabular}{lcc}
\hline Parameter & Estimate & $\mathrm{SE} \%$ \\
\hline Postoperative $\mathrm{CL}\left(\mathrm{ml} \mathrm{min}^{-1}\right)$ & 37.6 & 7.9 \\
Ratio of intra-operative $\mathrm{CL}$ to & 0.89 & 4.3 \\
postoperative CL & & \\
V1 (litre) & 1.27 & 13.6 \\
Ratio of intra-operative V1 to & 0.8 & 16.6 \\
postoperative V1 & & \\
$\mathrm{Q}$ (ml min ${ }^{-1}$ ) & 42.3 & 5.2 \\
V2 (litre) & 2.53 & 55.4 \\
Age of 50\% CL (weeks) & 7.36 & 16.6 \\
Parameter & Between-subject & $\mathrm{SE} \%$ \\
& variability & \\
$\omega^{2} \mathrm{CL}$ & 16.79 & 33.9 \\
$\omega^{2}$ V1 & 47.01 & 72.4 \\
Residual variability & Variance & $\mathrm{SE} \%$ \\
$\mathrm{~s}^{2}$ proportional & 0.03 & 27.9 \\
$s^{2}$ additive & 0.6 & 22.6 \\
\hline & &
\end{tabular}

Blood loss is a significant concern in children undergoing cranial vault reconstruction surgery. Large scalp dissections and the performance of large craniotomies and osteotomies, together with the potential for dural venous sinus bleeds, provide opportunities for significant intraoperative haemorrhage. Multiple strategies have been devised for reducing blood loss and transfusion in this population, including preoperative erythropoietin administration, ${ }^{34-37}$ reinfusion of shed blood, ${ }^{2}$ acute preoperative normovolemic haemodilution, ${ }^{34}{ }^{38}$ use of fibrinogen concentrates, ${ }^{39}$ prophylactic administration of fresh frozen plasma, ${ }^{24} 40$ and administration of antifibrinolytic drugs. ${ }^{5142}$ Of these, the use of antifibrinolytics has notable advantages. These drugs are simple to administer, are well tolerated, require no additional office visits or surveillance lab testing (when compared with erythropoietin), and require no additional equipment beyond an infusion pump (in contrast to cell saver or acute preoperative normovolemic haemodilution). Furthermore, there is a growing body of evidence supporting the efficacy of antifibrinolytics in infants and children undergoing craniofacial surgery, as two recent randomized, blinded clinical trials have shown the antifibrinolytic tranexamic acid (TXA), another synthetic lysine analogue, to be effective in reducing blood loss and transfusion requirements in this population. ${ }^{542}$

These recent clinical trials justify conduct of a prospective clinical trial of EACA to determine whether it is also effective in reducing blood loss. The PK data from this study will enable the use of a dosing strategy designed to achieve therapeutic drug concentrations, an essential element for the conduct of a valid efficacy study with EACA. If similarly efficacious, EACA would be a useful and less-expensive alternative to TXA (US $\$ 597$ for ten $100 \mathrm{mg} \mathrm{ml}^{-1} 10 \mathrm{ml}$ single-dose vials of TXA vs US $\$ 123$ for ten $100 \mathrm{mg} \mathrm{ml}^{-1} 10 \mathrm{ml}$ single-dose vials of EACA, personal communication with our hospital pharmacy). Having two efficacious antifibrinolytics would also be useful given the potential for interruptions in the availability of injectable medications. ${ }^{43-45}$

Unlike typical PK studies in volunteers, the subjects in this study underwent surgical procedures with significant blood loss. We hypothesized that a study drug was eliminated not only by renal and metabolic processes, but also through direct loss via haemorrhage. Modelling results, however, revealed that intraoperative $\mathrm{CL}$ was found to be

Table 5 Pre-/postoperative and intraoperative CL and V1 estimates for various weights without age adjustment

\begin{tabular}{|c|c|c|c|c|c|c|c|c|}
\hline $\begin{array}{l}\text { Weight } \\
\text { (kg) }\end{array}$ & $\begin{array}{l}\text { Pre-/post-op. } \\
\left.\text { CL (ml min }{ }^{-1}\right)\end{array}$ & $\begin{array}{l}\text { Pre-/post-op. CL } \\
\left(\mathrm{ml} \mathrm{kg}{ }^{-1} \mathrm{~min}^{-1}\right)\end{array}$ & 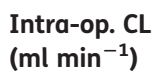 & $\begin{array}{l}\text { Intra-op. CL (ml } \\
\mathrm{kg}^{-1} \mathrm{~min}^{-1} \text { ) }\end{array}$ & $\begin{array}{l}\text { Pre-/post-op. } \\
\text { V1 (litre) }\end{array}$ & $\begin{array}{l}\text { Pre-/post-op. } \\
\text { V1 (litre } \mathbf{k g}^{-1} \text { ) }\end{array}$ & $\begin{array}{l}\text { Intra-op. V1 } \\
\text { (litre) }\end{array}$ & $\begin{array}{l}\text { Intra-op. V1 } \\
\text { (litre } \mathbf{k g}^{-1} \text { ) }\end{array}$ \\
\hline 1 & 7.35 & 7.35 & 6.54 & 6.54 & 0.14 & 0.14 & 0.12 & 0.12 \\
\hline 5 & 24.56 & 4.91 & 4.37 & 0.87 & 0.72 & 0.14 & 0.58 & 0.12 \\
\hline 10 & 41.31 & 4.13 & 3.68 & 0.37 & 1.44 & 0.14 & 1.15 & 0.12 \\
\hline 15 & 56.00 & 3.73 & 3.32 & 0.22 & 2.16 & 0.14 & 1.73 & 0.12 \\
\hline 25 & 82.14 & 3.29 & 2.92 & 0.12 & 3.60 & 0.14 & 2.88 & 0.12 \\
\hline 50 & 138.14 & 2.76 & 2.46 & 0.05 & 7.20 & 0.14 & 5.76 & 0.12 \\
\hline 70 & 177.79 & 2.54 & 2.26 & 0.03 & 10.08 & 0.14 & 8.06 & 0.12 \\
\hline
\end{tabular}



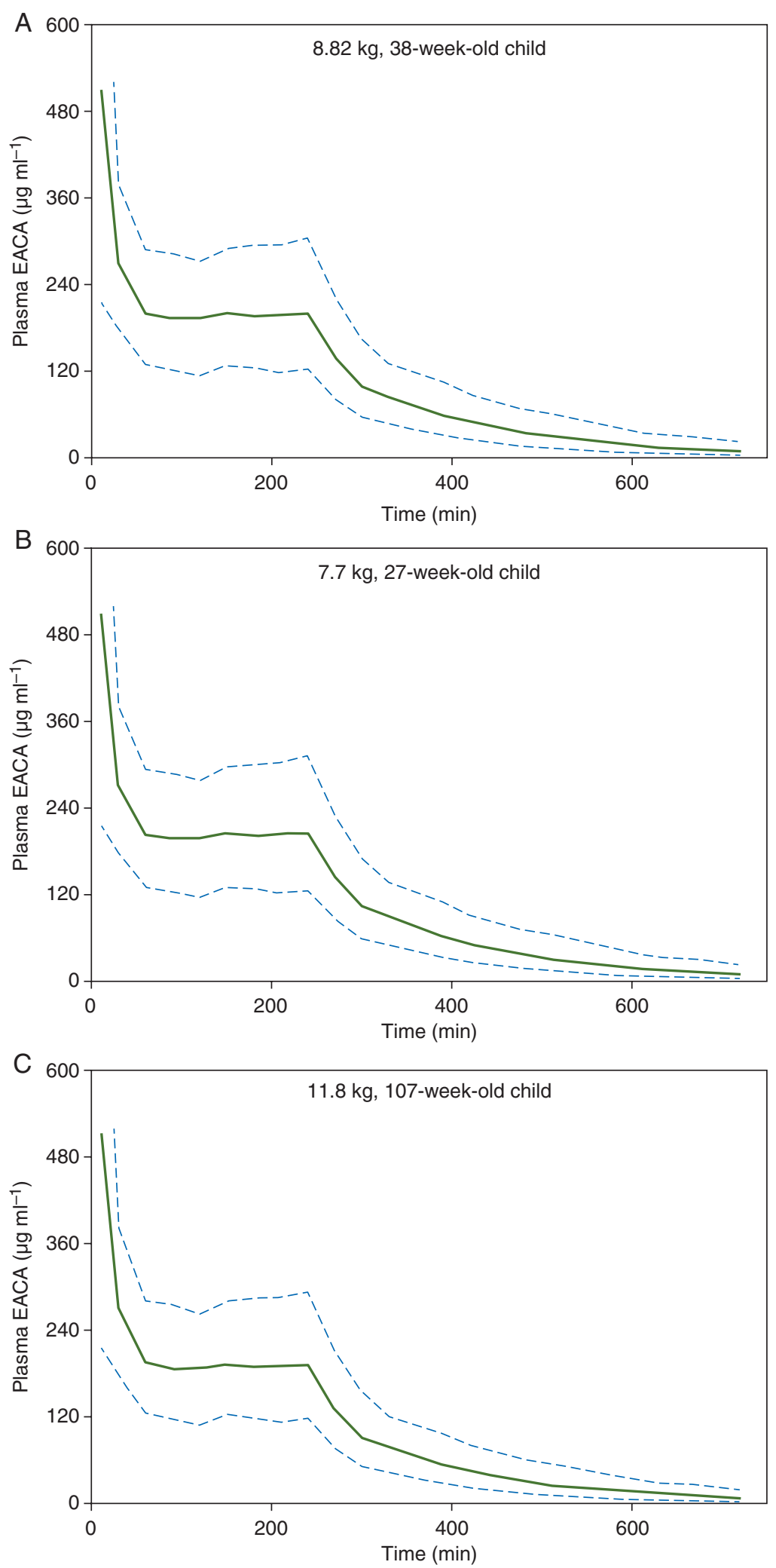

Fig 4 Simulated plasma EACA concentrations ( $\mu \mathrm{g} \mathrm{ml}^{-1}$ ) after a $100 \mathrm{mg} \mathrm{kg}^{-1}$ bolus over 10 min followed by a $40 \mathrm{mg} \mathrm{kg}^{-1} \mathrm{~h}^{-1}$ infusion for $4 \mathrm{~h}$ ( $240 \mathrm{~min}$ ) in a $8.82 \mathrm{~kg}$, 38-week-old child (A), the youngest subject in the cohort ( $7.7 \mathrm{~kg}, 27$ weeks; B) and the oldest subject in the cohort (11.8 $\mathrm{kg}, 107$ weeks; c), who all experienced an operative procedure of $240 \mathrm{~min}$. The solid line represents the median concentrations. The dashed lines represent the 2.5 th (lower) and 97.5 th (upper) percentiles. 
less than postoperative CL. This finding is not completely inconsistent with bleeding as an elimination mechanism, in that the model results may be simply reflecting the net effect of a possible increased $C L$ due to blood loss and decreased $\mathrm{CL}$ due to other confounding intra-operative factors. The magnitude of the intra-operative decrease in $\mathrm{CL}$ corresponds to an expected increase in steady-state concentrations of $\sim 15 \%$ during this period, relative to the postoperative period.

\section{Limitations}

Although sample size was a potential limitation of this study, the structural PK parameters were precisely estimated. Previous PK studies of EACA in adults have included 6 subjects, ${ }^{9} 10$ subjects, ${ }^{33}$ and 16 subjects. ${ }^{31}$ The only available PK study in children involved nine subjects who underwent procedures on cardiopulmonary bypass. ${ }^{22}$ There are many conditions in the operating theatre that may impact clearance and volume of distribution, such as blood loss, fluid administration, anaesthetic-induced decreases in blood pressure and cardiac output that may result in decreased organ blood flow. As described earlier in the Methods section, this makes unique estimation of any one of these effects on parameter estimates unidentifiable; therefore we used the intra-operative period as a categorical variable to estimate the changes in $\mathrm{CL}$.

We did not perform thromboelastography to assess the effects of EACA in this study. The therapeutic goal of intraoperative EACA administration is to achieve plasma levels that completely inhibit fibrinolysis. This plasma concentration was determined to be $130 \mu \mathrm{g} \mathrm{ml}^{-1}$ by in vitro testing of adult plasma by McNicol and colleagues. ${ }^{31}$ These findings were recently independently confirmed. ${ }^{46}$ Interestingly, Goobie and colleagues ${ }^{5}$ showed no differences in thromboelastographic measurements between placebo and TXA groups despite therapeutic plasma TXA concentrations and a $40 \%$ reduction in transfusion. Based on the above, thromboelastography was unlikely to have been a useful measurement in the present study. It should also be noted that we have assumed that the therapeutic EACA plasma concentration in adults is also therapeutic in infants and children, whose coagulation and fibrinolytic systems are still developing. ${ }^{47} 48$ The available evidence shows that significantly lower plasma concentrations of EACA are required to completely prevent fibrinolysis in neonatal plasma. ${ }^{46}$

\section{Conclusions}

Epsilon-aminocaproic acid PKs is influenced by weight, age, and perioperative conditions. Weight-based dosing in this population is appropriate, and based on the modelling from this study, a loading dose of $100 \mathrm{mg} \mathrm{kg}^{-1}$ followed by a CIVI of $40 \mathrm{mg} \mathrm{kg}^{-1} \mathrm{~h}^{-1}$ is appropriate to maintain target plasma EACA concentrations in patients 6-24 months of age undergoing these procedures. EACA was well tolerated and no adverse events were attributed to its administration. A prospective efficacy trial using the dosing recommendations from this study evaluating the efficacy of EACA in this population is suggested.

\section{Acknowledgement}

The authors wish to acknowledge and thank Ganesh Moorthy, PhD, who performed the EACA assays.

\section{Declaration of interest}

None declared.

\section{Funding}

This work was funded in part by the Thomas B. McCabe and Jeannette E. Laws McCabe Fund Pilot Award and by NIH/NCRR UL1-RR-0204134.

\section{Authors' contributions}

P.A.S.: study design, conduct of study, data collection, data analysis, manuscript preparation; A.F.Z.: study design, conduct of study, data analysis, manuscript preparation; J.E.F.: study design, conduct of study, manuscript preparation; L.G.M.: conduct of study, manuscript preparation; E.M.S., E.Y.P., and T.K.G.: conduct of study, data collection; M.R.G.: data analysis, manuscript preparation; J.A.T. and S.P.B.: conduct of study; M.S.S.: study design, manuscript preparation.

\section{References}

1 White N, Marcus R, Dover S, et al. Predictors of blood loss in front-orbital advancement and remodeling. J Craniofac Surg 2009; 20: 378-81

2 Orliaguet GA, Bruyere M, Meyer PG, Blanot S, Renier D, Carli PA. Comparison of perioperative blood salvage and postoperative reinfusion of drained blood during surgical correction of craniosynostosis in infants. Paediatr Anaesth 2003; 13: 797-804

3 Stricker P, Shaw T, DeSouza D, et al. Blood loss, replacement, and associated morbidity in infants and children undergoing craniofacial surgery. Pediatr Anesth 2010; 20: 150-9

4 Stricker PA, Cladis FP, Fiadjoe JE, McCloskey JJ, Maxwell LG. Perioperative management of children undergoing craniofacial reconstruction surgery: a practice survey. Pediatr Anesth 2011; 21: 1026-35

5 Goobie SM, Meier PM, Pereira LM, et al. Efficacy of tranexamic acid in pediatric craniosynostosis surgery: a double-blind, placebo-controlled trial. Anesthesiology 2011; 114: 862-71

6 Dodd RY, Notari EPt, Stramer SL. Current prevalence and incidence of infectious disease markers and estimated windowperiod risk in the American Red Cross blood donor population. Transfusion 2002; 42: 975-9

7 Hendrickson JE, Hillyer CD. Noninfectious serious hazards of transfusion. Anesth Analg 2009; 108: 759-69

8 Vamvakas EC, Blajchman MA. Transfusion-related immunomodulation (TRIM): an update. Blood Rev 2007; 21: 327-48

9 Frederiksen MC, Bowsher DJ, Ruo TI, Henthorn CT, Green D, Atkinson AJ. Kinetics of epsilon-aminocaproic acid distribution, elimination, and antifibrinolytic effects in normal subjects. Clin Pharmacol Ther 1984; 35: 387-93 
10 Collen D. On the regulation and control of fibrinolysis. Edward Kowalski Memorial Lecture. Thromb Haemost 1980; 43: 77-89

11 Williams GD, Bratton SL, Riley EC, Ramamoorthy C. Efficacy of epsilon-aminocaproic acid in children undergoing cardiac surgery. J Cardiothorac Vasc Anesth 1999; 13: 304-8

12 Thompson GH, Florentino-Pineda I, Poe-Kochert C, Armstrong DG, Son-Hing JP. The role of amicar in same-day anterior and posterior spinal fusion for idiopathic scoliosis. Spine 2008; 33: 2237-42

13 Chauhan S, Kumar BA, Rao BH, et al. Efficacy of aprotinin, epsilon aminocaproic acid, or combination in cyanotic heart disease. Ann Thorac Surg 2000; 70: 1308-12

14 Florentino-Pineda I, Blakemore LC, Thompson GH, Poe-Kochert C, Adler P, Tripi P. The effect of epsilon-aminocaproic acid on perioperative blood loss in patients with idiopathic scoliosis undergoing posterior spinal fusion. Spine 2001; 26: 1147-51

15 Florentino-Pineda I, Thompson GH, Poe-Kochert C, Huang RP, Haber LL, Blakemore LC. The effect of amicar on perioperative blood loss in idiopathic scoliosis: the results of a prospective, randomized, double-blind study. Spine 2004; 29: 233-8

16 Thompson GH, Florentino-Pineda I, Poe-Kochert C. The role of amicar in decreasing perioperative blood loss in idiopathic scoliosis. Spine 2005; 30: S94-S9

17 Nilsson IM, Sjoerdsma A, Waldenstrom J. Antifibrinolytic activity and metabolism of 6-aminocaproic acid in man. Lancet 1960; 1: $1322-6$

18 Bennett-Guerrero E, Sorohan JG, Canada AT, et al. Epsilonaminocaproic acid plasma levels during cardiopulmonary bypass. Anesth Analg 1997; 85: 248-51

19 Butterworth J, James RL, Lin Y, Prielipp RC, Hudspeth AS. Pharmacokinetics of epsilon-aminocaproic acid in patients undergoing aortocoronary bypass surgery. Anesthesiology 1999; 90: 1624-35

20 Butterworth J, James RL, Lin YA, Bennett J, Prielipp RC. Gender does not influence epsilon-aminocaproic acid concentrations in adults undergoing cardiopulmonary bypass. Anesth Analg 2001; 92: $1384-90$

21 Fish SS, Pancorbo S, Berkseth R. Pharmacokinetics of epsilonaminocaproic acid during peritoneal dialysis. J Neurosurg 1981; 54: $736-9$

22 Ririe DG, James RL, O'Brien JJ, et al. The pharmacokinetics of epsilon-aminocaproic acid in children undergoing surgical repair of congenital heart defects. Anesth Analg 2002; 94: 44-9

23 Kearney RA, Rosales JK, Howes WJ. Craniosynostosis: an assessment of blood loss and transfusion practices. Can J Anaesth 1989; 36: 473-7

24 Stricker PA, Fiadjoe JE, Davis AR, et al. Reconstituted blood reduces blood donor exposures in children undergoing craniofacial reconstruction surgery. Pediatr Anesth 2011; 21: 54-61

25 Anderson BJ, McKee AD, Holford NH. Size, myths and the clinical pharmacokinetics of analgesia in paediatric patients. Clin Pharmacokinet 1997; 33: 313-27

26 Harrell F. Regression Modeling Strategies. New York: Springer, 2001

27 Ribbing J, Jonsson EN. Power, selection bias and predictive performance of the population pharmacokinetic covariate model. J Pharmacokinet Pharmacodyn 2004; 31: 109-34

28 Alkjaersig N, Fletcher AP, Sherry S. Epsilon-Aminocaproic acid: an inhibitor of plasminogen activation. J Biol Chem 1959; 234: 832-7

29 Ablondi FB, Hagan JJ, Philips M, DeRenzo EC. Inhibition of plasmin, trypsin, and the streptokinase-activated fibrinolytic system by epsilon-aminocaproic acid. Arch Biochem Biophys 1959; 82: 153-60

30 Nilsson IM. Clinical pharmacology of aminocaproic and tranexamic acids. J Clin Pathol Suppl (R Coll Pathol) 1980; 14: 41-7

31 McNicol G, Fletcher A, Alkjaersig N, Sherry S. The absorption, distribution, and excretion of epsilon-aminocaproic acid following oral or intravenous administration to man. J Lab Clin Med 1962; 59: $15-24$

32 Andersson L, Nilsson I, Collen S, Grandstrand B, Melander B. Role of urokinase and tissue activator in sustaining bleeding and the management thereof with EACA and AMCA. Ann N Y Acad Sci 1968; 146: 642-58

33 Dvorchik BH, Katlic KL, Hayes AH Jr., Eyster ME. Effect of probenecid on the kinetics of epsilon-aminocaproic acid. Clin Pharmacol Ther 1980; 28: 223-8

34 Meneghini L, Zadra N, Aneloni V, Metrangolo S, Faggin R, Giusti F. Erythropoeitin therapy and acute preoperative normovolaemic haemodilution in infants undergoing craniosynostosis surgery. Paediatr Anaesth 2003; 13: 392-6

35 Fearon JA, Weinthal J. The use of recombinant erythropoietin in the reduction of blood transfusion rates in craniosynostosis repair in infants and children. Plast Reconstr Surg 2002; 109: 2190-6

36 Helfaer MA, Carson BS, James CS, Gates J, Della-Lana D, Vander Kolk C. Increased hematocrit and decreased transfusion requirements in children given erythropoietin before undergoing craniofacial surgery. J Neurosurg 1998; 88: 704-8

37 Meara JG, Smith EM, Harshbarger RJ, Farlo JN, Matar MM, Levy ML. Blood-conservation techniques in craniofacial surgery. Ann Plast Surg 2005; 54: 525-9

38 Hans P, Collin V, Bonhomme V, Damas F, Born JD, Lamy M. Evaluation of acute normovolemic hemodilution for surgical repair of craniosynostosis. J Neurosurg Anesthesiol 2000; 12: 33-6

39 Haas T, Fries D, Velik-Salchner C, Oswald E, Innerhofer P. Fibrinogen in craniosynostosis surgery. Anesth Analg 2008; 106: 725-31

40 Hildebrandt $B$, Machotta A, Riess $\mathrm{H}$, et al. Intraoperative freshfrozen plasma versus human albumin in craniofacial surgery- a pilot study comparing coagulation profiles in infants younger than 12 months. Thromb Haemost 2007; 98: 172-7

41 D'Errico CC, Munro HM, Buchman SR, Wagner D, Muraszko KM. Efficacy of aprotinin in children undergoing craniofacial surgery. J Neurosurg 2003; 99: 287-90

42 Dadure C, Sauter M, Bringuier S, et al. Intraoperative tranexamic acid reduces blood transfusion in children undergoing craniosynostosis surgery: a randomized double-blind study. Anesthesiology 2011; 114: 856-61

43 Jensen V, Rappaport BA. The reality of drug shortages-the case of the injectable agent propofol. N Engl J Med 2010; 363: 806-7

44 De Oliveira GS Jr., Theilken LS, McCarthy RJ. Special article: shortage of perioperative drugs: implications for anesthesia practice and patient safety. Anesth Analg 2011; 113: 1429-35

45 Mullins TD, Cook AM. Drug shortages: causes and cautions. Orthopedics 2011; 34: 712-4

46 Yurka HG, Wissler RN, Zanghi CN, Liu X, Tu X, Eaton MP. The effective concentration of epsilon-aminocaproic acid for inhibition of fibrinolysis in neonatal plasma in vitro. Anesth Analg 2010; 111: 180-4

47 Albisetti M. The fibrinolytic system in children. Semin Thromb Hemost 2003; 29: 339-48

48 Kuhle S, Male C, Mitchell L. Developmental hemostasis: pro- and anticoagulant systems during childhood. Semin Thromb Hemost 2003; 29: 329-38

Handling editor: M. M. R. F. Struys 